\title{
Primary Tumor Resection in Asymptomatic Colorectal Cancer Patients With Unresectable Metastases: Can It Improve Survival?
}

\author{
Myong Hoon Ihn \\ Department of Surgery, Soonchunhyang University Seoul Hospital, Soonchunhyang University College of Medicine, Seoul, Korea
}

\section{See Articles on Page 94-100}

Colorectal cancer (CRC) is one of the most frequent cancer types and a common cause of cancer-related death. Various strategies have now been developed for the treatment of CRC, such as surgery, chemotherapy, radiotherapy, targeted, and immunotherapy. Despite advances in treatment, relapse occurs in $\sim 30 \%$ of states I to III and $65 \%$ of stage IV CRC patients [1]. In addition, approximately $20 \%$ of CRC patients are diagnosed with stage IV at the time of initial diagnosis [2]. According to the current treatment guidelines, surgical resection combined with chemotherapy is the treatment of choice for patients with resectable metastases, whereas chemotherapy is the treatment of choice for patients with unresectable metastases [3]. However, primary tumor resection (PTR) or palliative surgery are required for symptomatic relief and further medical treatment in patients with unresectable metastases who present with symptoms related to their primary tumors, such as intestinal obstruction, significant bleeding, fistulas, or perforation.

The role of PTR remains controversial in asymptomatic CRC patients with unresectable metastases. Traditionally, PTR in asymptomatic patients with unresectable metastases has been performed for the goal of avoiding late complications in selective patients, although there was little evidence to support this approach. Recently, there were many studies to evaluate the effectiveness of PTR on survival in asymptomatic patients with unresectable metastases [4-

Correspondence to: Myong Hoon Ihn, M.D.

Department of Surgery, Soonchunhyang University Seoul Hospital, Soonchunhyang University College of Medicine, 59 Daesagwan-ro, Yongsan-gu, Seoul 04401, Korea

Tel: +82-2-710-3234, Fax: +82-2-710-3088

E-mail: income78@hanmail.net

ORCID: https://orcid.org/0000-0002-9522-401X

(C) 2021 The Korean Society of Coloproctology

This is an open-access article distributed under the terms of the Creative Commons Attribution NonCommercial License (https://creativecommons.org/licenses/by-nc/4.0) which permits unrestricted noncommercial use, distribution, and reproduction in any medium, provided the original work is properly cited.
9]. These studies reported that PTR could provide significant survival benefits. In addition, a recent meta-analysis, which included 21 retrospective studies with a total of 44,226 patients, revealed that the mortality rate was lower with PTR than with chemotherapy alone [4]. However, their results were not free from selection bias because of a significant imbalance in the distribution of confounders, and most studies were single-center studies.

Currently, several randomized controlled trials (RCTs) are ongoing to address this issue [10-13]. However, it does not seem easy to draw conclusions early. As the authors mentioned, all RCTs carry numerous intrinsic difficulties caused by strict eligibility criteria, patient preferences, and clinician bias lead to poor acceptance of the randomized assignment and difficulties in patient accrual.

The authors have suggested that asymptomatic CRC patients with unresectable metastases could gain a survival benefit from upfront PTR [14]. In this study, the median survival of the PTR group was 18 months and that of the non-PTR group was 15 months, and it was statistically insignificant $(\mathrm{P}=0.152)$. However, in the multivariate weighted Cox regression, the results indicated that the PTR showed a significantly decreased risk of cancer-related death (hazard ratio, 0.61; 95\% confidence interval, 0.40 0.94). Although this study may also have a potential for selection bias because of the retrospective study nature, it is meaningful that the authors try to evaluate the effectiveness of PTR using the inverse probability of treatment weighting' method, which is a recently emerging statistical tool to minimize selection bias by adjusting the baseline confounders. Ongoing RCTs and further largescale prospective studies will be helpful in verifying the results.

\section{CONFLICT OF INTEREST}

No potential conflicts of interest relevant to this article were reported.

\section{REFERENCES}

1. Tanis PJ. Refining the role of adjuvant chemotherapy in stage III 
colon cancer. Colorectal Dis 2019;21:135-6.

2. Hu CY, Bailey CE, You YN, Skibber JM, Rodriguez-Bigas MA, Feig BW, et al. Time trend analysis of primary tumor resection for stage IV colorectal cancer: less surgery, improved survival. JAMA Surg 2015;150:245-51.

3. National Comprehensive Cancer Network (NCCN). Clinical practice guidelines in oncology (NCCN guidelines): colon cancer [Internet]. Plymouth Meeting, PA: NCCN; c2021 [cited 2020 Jun 21]. Available from: https://www.nccn.org/professionals/physician_ gls/pdf/colon.pdf.

4. Clancy C, Burke JP, Barry M, Kalady MF, Calvin Coffey J. A meta-analysis to determine the effect of primary tumor resection for stage IV colorectal cancer with unresectable metastases on patient survival. Ann Surg Oncol 2014;21:3900-8.

5. Ahmed S, Fields A, Pahwa P, Chandra-Kanthan S, Zaidi A, Le D, et al. Surgical resection of primary tumor in asymptomatic or minimally symptomatic patients with stage IV colorectal cancer: a Canadian province experience. Clin Colorectal Cancer 2015;14:e41-7.

6. Xu Z, Becerra AZ, Fleming FJ, Aquina CT, Dolan JG, Monson JR, et al. Treatments for stage IV colon cancer and overall survival. J Surg Res 2019;242:47-54.

7. Kim MS, Chung M, Ahn JB, Kim CW, Cho MS, Shin SJ, et al. Clinical significance of primary tumor resection in colorectal cancer patients with synchronous unresectable metastasis. J Surg Oncol 2014;110:214-21.

8. Ferrand F, Malka D, Bourredjem A, Allonier C, Bouché O, Louafi $S$, et al. Impact of primary tumour resection on survival of patients with colorectal cancer and synchronous metastases treated by chemotherapy: results from the multicenter, randomised trial Fédération Francophone de Cancérologie Digestive 9601. Eur J
Cancer 2013;49:90-7.

9. Xu J, Ma T, Ye Y, Pan Z, Lu D, Pan F, et al. Surgery on primary tumor shows survival benefit in selected stage IV colon cancer patients: a real-world study based on SEER database. J Cancer 2020; 11:3567-79.

10. 't Lam-Boer J, Mol L, Verhoef C, de Haan AF, Yilmaz M, Punt CJ, et al. The CAIRO4 study: the role of surgery of the primary tumour with few or absent symptoms in patients with synchronous unresectable metastases of colorectal cancer: a randomized phase III study of the Dutch Colorectal Cancer Group (DCCG). BMC Cancer 2014;14:741.

11. Rahbari NN, Lordick F, Fink C, Bork U, Stange A, Jäger D, et al. Resection of the primary tumour versus no resection prior to systemic therapy in patients with colon cancer and synchronous unresectable metastases (UICC stage IV): SYNCHRONOUS. A randomised controlled multicentre trial (ISRCTN30964555). BMC Cancer 2012;12:142.

12. Moritani K, Kanemitsu Y, Shida D, Shitara K, Mizusawa J, Katayama $\mathrm{H}$, et al. A randomized controlled trial comparing primary tumour resection plus chemotherapy with chemotherapy alone in incurable stage IV colorectal cancer: JCOG1007 (iPACS study). Jpn J Clin Oncol 2020;50:89-93.

13. Kim CW, Baek JH, Choi GS, Yu CS, Kang SB, Park WC, et al. The role of primary tumor resection in colorectal cancer patients with asymptomatic, synchronous unresectable metastasis: study protocol for a randomized controlled trial. Trials 2016;17:34.

14. Doah KY, Shin US, Jeon BH, Cho SS, Moon SM. The impact of primary tumor resection on survival in asymptomatic colorectal cancer patients with unresectable metastases. Ann Coloproctol 2021;37:94-100. 